\title{
A.C.S. van Heel: teacher and inspirator of technical optics
}

\section{Simons}

C. A. J. Simons, "A.C.S. van Heel: teacher and inspirator of technical optics," Proc. SPIE 3190, Fifth International Topical Meeting on Education and Training in Optics, (8 December 1997); doi: 10.1117/12.294379

Event: Fifth International Topical Meeting on Education and Training in Optics, 1997, Delft, Netherlands 


\title{
A.C.S. van Heel, Teacher and Inspirator of Technical Optics \\ C.A.J. Simons \\ Erasmus University, Rotterdam School of Management
}

\begin{abstract}
Summary
Professor Bram van Heel (1899-1966) initiated applicable optical techniques in The Netherlands. His optical aligning methods helped to accelerate the rebuilding of his country after the second world war.

He lowered the threshold to successful optical design by creating, together with his pupils, practical formulae and algorithms, which were dug out of the existing, but rather forbidding, theory of geometrical optics. The resulting optical calculation schemes enabled designers, equipped with electromechanical and/or the first small "modern" computers to create optical systems that were used worldwide. He also helped to establish state of the art optical industry in The Netherlands. Many of his pupils were and are working in optics, mainly in The Netherlands and the U.S.A., but also in the Middle East and South East Asia.

As talented teacher he popularized optics in the technical world. Even students not majoring in physics attended his attractive lectures, spiced with experiments and witticisms.

The prominent opticists of his time were his friends. Therefore it is not surprising that Van Heel was among the founding fathers of the ICO, which was established during an optical conference in 1948 in Delft, and of the thentime European journal Optica Acta, which came into existence in 1954.

In the following paragraphs we will briefly give some details on Van Heel's optical career, his research, its spin-off, and the impact of his teaching.
\end{abstract}

\section{Career in optics}

Van Heel studied physics at Leiden University. At that time, Ehrenfest, the successor to Nobel laureate H.A.Lorentz held the chair of theoretical physics. During many years, apart from developing his famous electron theory, Lorentz was active in theoretical studies linking optical theorems of imaging and refraction to Maxwell's electromagnetic work, starting with his $\mathrm{Ph} . \mathrm{D}$. thesis. Whether Lorentz, who was always mentioned with great awe and respect by Van Heel, influenced him to engage on optical research, is unknown to me. Facts are, that his Ph.D. thesis discusses optical techniques to determine characteristics of solids at extremely low temperatures and that he worked one year in the optics laboratory of Fabry in Paris. Although the thentime Dutch educational system required some proficiency in three modern languages (English, French, German), I assume that his fluency in French, which was a real asset in his later years as president of international optical meetings and conferences, was acquired during that year in Paris.

As young Ph.D. he began in 1925 to work at the Technical University in Delft. He went through the ranks, starting as tutor, lecturing on various subjects such as mechanics and heat, besides optics. During that time, the thirties, the nazis came into power in Germany, leading to an exodus of artists and scientists. We found evidence of Van Heel's moral and practical attitude in a handwritten dedication in Max Herzberger's book Modern Geometrical Optics by the author: "To Bram van Heel, who so generously helped me when I had to flee nazi Germany". Van Heel offered Herzberger his own room at the university, freeing the latter from immediate worries 
about food and shelter, before he could continue his flight via the U.K. to the U.S.A. Van Heel was in 1938 appointed lecturer in optics, to become in 1947 full-time professor in the Faculty of Technical Physics, holding the chair in Optics till his untimely death in 1966.

His friendly extravert personality, together with his proficiency in foreign languages made him a natural candidate after the second worldwar for official positions in optical and academic circles, of which the most important were: President of the International Commission for Optics (ICO) from 1950 until 1956, where he encouraged and supported the reappearance and acceptance of the German opticists. He became Vice Rector of the Technical University in 1963-'64. Apart from functioning at official meetings, he used his charm and expertise to "arrange" results, which he considered worthwhile to obtain. A good example is his winning over of the officers of the Optical Society in Great Britain, to support the creation of the European optical journal Optica Acta. Already in many meetings, inside and outside the ICO, the subject had extensively been discussed. Although the French and the German opticists, together with their colleagues in smaller countries were convinced that such a journal was desirable, the British didn't like the idea of having to sacrifice the important status of their Transactions of the Optical Society. Without the backing of the "Big Three" in European optics, the journal would not come to life, as Van Heel very well knew. Therefore, he asked "meekly" to be allowed to discuss personally once more this subject with the officers of the British Optical Society. He was invited to come to the U.K. and attend part of a meeting of the officers. This meeting took place in the building of the Royal Society in an impressive room, decorated with the portraits of Britain's scientific heroes. The chairman welcomed Van Heel and offered him a seat under the portrait of Sir Isaac Newton. When asked to present his views "once more", Van Heel sensed that the officers would politely listen to his words and would send him home with soothing, delaying, statements such as: "We will certainly put this matter on the agenda of the next meeting of the Optical Society blah blah", and send him home without any positive result. As he felt inspired by the great opticist Newton hanging behind him, he asked the chairman to be allowed to put to each officer a question, before engaging on details regarding the managing of a European scientific journal. As this request could of course not be refused, Van Heel then asked each officer, one after the other and the chairman as the last man: "Would it not be wonderful, after two worldwars, to unite the European scientists in optics, by means of a European optical journal?". And no one dared to say no! After that, details could be discussed, and this stumbling block on the road to Optica Acta had been dealt with.

Because of his widely recognized optical expertise, Van Heel and his department played a prominent role in wider circles than just those of science and university. He was already as young lecturer involved in industrial enterprises where optics was one of the disciplines, needed in designing and manufacturing their endproducts.

In 1939 he got involved in N.V. Optische Industrie "De Oude Delft", as it was called in those days, and Van Heel gave advice on optical design and the necessary algorithms, to help their thentime inexperienced design department. As a good tactician and instructor, he suggested during the German occupation in Worldwar II to design a nineteen element microscope objective and to build and test a few prototypes. It was an inconspicuous, normal activity for an optical industry, with two 
positive results, namely: 1) After designing, constructing and testing such a system, the design department had gained enough expertise and confidence to stand on its own legs, 2) This microscope objective was completely useless to any party, in particular the German occupation force. A second industry in Delft, Nonius, which designed and manufactured various precision products either as endproduct or as subcontractor, profited also from Van Heel's expertise and geographical nearness. Both mentioned companies, together with others, are today integrated in "Delft Instruments".

Likewise, the establishment of the Optics Department of the Institute of Applied Physics TNO-TPD (a co-operation between the Faculty of Technical Physics and the National Applied Scientific Research Corporation TNO) was promoted by Van Heel. Their output has contributed significantly to all kinds of activities, ranging from space research via environmental remote sensing to forensic optics.

Other signs of recognition are e.g. his election as Fellow of the American Optical Society, and as Fellow of the Hollandsche Maatschappij der Wetenschappen te Haarlem, (Dutch Society of Sciences), where his contributions on the history of optics (Huygens and Newton) show his wide interests and erudition. The longstanding relation of his optical department with the astronomy department of Utrecht University, in particular for design and construction of optical instruments for their solar eclipse expeditions is another example of his "spreading the gospel of optics".

\section{Research}

Three main subjects can be identified in Van Heel's research activities: 1) The creation of useful and handy algorithms, formulae and calculation schemes for designing optical systems, 2) The actual designing of optical systems, including rule of thumb pre-design reasoning and tolerancing, 3) Alignment methods, tests and equipment.

1) During his stay with Fabry in Paris, Van Heel attended the lectures on optical design given by Chrétien. The state of the art at that time was mainly a mixture of formulae, based on conventional trigonometric raytracing of meridional rays, the Seidel third order aberration coëfficients and the Gaussian paraxial theory, all of the nineteenth century. The cumbersome way of calculating is e.g. illustrated in the books of Conrady, where continuously a battle is fought to maintain the necessary accuracy in raytracing calculations. As image spots in most cases should be in the order of magnitude of microns, and system parameters (radii of curvature, separations between and thicknesses and diameters of optical elements) are mostly in the order of magnitude of centimeters or larger, six- or seven decimal place trigonometric tables had to be used and within the process of tracing one ray through a system, at least two sets of formulae were needed, one for small radii of curvature and one for large radii and flat surfaces. Aspherical surfaces were sometimes applied, but mostly conical sections and only for close to paraxial imaging purposes. In Van Heel's notebooks we find many excercises in order to compare the usefulness of different formula, of which Seidel's coëfficients and Dennis Taylor's bending of thin lenses passed the acid test. However, in raytracing the inherent superiority of Thomas Smith's algorithms induced Van Heel to study, together with Ph.D. students, very diligently all of Smith's always cryptic and sometimes slightly mysterious research results. With 
the advent of electromechnical calculation machines (such as Madas, Monroe, etc.) more rapid optical calculations became possible to meet the increasing demand for optical systems with high apertures and large image fields. An essential requirement however had to be fulfilled, namely the creation of easy to use routine algorithms such, that novices in optics and those who only occasionally had to evaluate or (pre)design an optical system could master quickly the three step process of paraxial, third order (occasionally even fifth order), and raytracing calculations. In the nineteen forties and -fifties these algorithms were created and tested, all based on Smith's theory on aberration coëfficients and his work on raytracing. An important feature of both paraxial and aberration calculating schemes were their built-in correctness tests, which enabled even students and non academic professional scientific arithmeticians to calculate routinely optical system characteristics. For raytracing, Smith's ideas on how to get six-decimal accuracy with four-decimal tables, were also developed into practical schemes, albeit that in most cases only meridional rays were traced through spherical and/or flat surfaces. An electromechanical computer for the optical three step process, with "soldered-in" software, was developed and constructed. Its "Central Processing Unit" consisted of an enormous collection of telephone relays and, I guess, hundreds of meters of electric wire connections. Input was achieved through reading data on telex tape, output was typed on a typewriter, whose keys were activated by magnetic coils. The algorithms, in particular those for raytracing were modified for automatic calculations, which later came in handy with the advent of electronic computers. The machine's appearance and its clattering and rattling during operation reminded me of the then well-known Rube Goldberg cartoons of fantastic contraptions appearing in the Saturday Evening Post,when I came to know it in the early sixties as an operational but rarely used tool because of the then available commercial electronic computers. This machine was given the name Testudo, which is the latin word for turtle, because it took ten minutes to trace one ray through one surface, whereas a trained human could do it within four minutes. However, Van Heel used to say: "Testudo works during the night, and then I sleep."

2) The above mentioned developments lead to many designs by scientists and students of the optics department. As we will discuss later, Van Heel favoured satisfactory results, using the simplest possible means. There was a tradition to "milk" every traced ray for information about e.g. astigmatism, coma, optical pathlength. Many systems were designed and manufactured, varying from beautifully corrected objectives and eyepieces for telescopes and periscopes, a complex magnifier for a visually handicapped man, via pathological lenses to illustrate e.g. pure coma or to use spherical aberration for alignment systems, to wide-angle lenses, a horizon camera objective and mirror- and catadioptric systems for medical and astronomical purposes. One example of his trying to get useful results by simple designs is his socalled One Radius Doublet. By applying a certain range of crown glass refractive indices, a certain ratio between the refractive indices of crown and flint refractive indices and another for their respective dispersion numbers, a cemented doublet consisting of an equiconvex and a convex-plano element, corrected for chromatic and spherical aberration and reasonably corrected for coma is obtained. The optical glasses are to be found 
in any optical glass catalogue, and the curved surfaces of the two elements are, to quote Van Heel: "each other's testglasses and when you make three doublets, the flat surfaces are also each other's testglasses". In many cases this simple doublet is good enough, and it can be designed on the back of an envelope. Especially the co-operation between the astronomers in Utrecht and the opticists in Delft is worth mentioning. The shadow of the moon, in case it hits the earth during a solar eclipse, is generally not located next door. The costs for an expedition and for equipment tended to surpass easily the limited budget of the astronomers. A mutualistic symbiosis was promoted and achieved, mainly by Van Heel: Utrecht specified their requirements for "zero cost" spectrographs, telescopic camera objectives, telelenses, etc. and a fourth- or fifth year student got a challenging project by designing, testing, and sometimes even operating the required system in the field.

The need for anti-reflection coatings triggered the development of instruments to monitor the evaporation and deposition, in a vacuum system, of coating material onto optical surfaces. This resulted in a very accurate method for the determination of phase retardations in coatings and hence in the manufacturing, on laboratory scale, of multilayer stacks for laser mirrors, beamsplitters, etc.

A good, albeit small, optical workshop and coating room made the realization of designs possible. Van Heel insisted on in-house manufacturing, in order to make visible, at an early moment, possible manufacturing problems, for the enlightenment of the design student. Another reason was, that no optical company is willing to manufacture a few prototypes cheaply.

3) The earlier mentioned preference of Van Heel for simple means, has lead to surprisingly accurate alignment methods and equipment. It all started with his dissatisfaction of the then existing aligning techniques, using either mechanical means (steel wires, sighting of pegs through holes) or optical ones (expensive, but intrinsically unreliable telescopes and collimators), with repectively sags, wind sensitivity and the need to refocus telescopes when surveying the line or plane to be generated. One of his motto's was: "Turn your optical ennemies into friends". In this case he meant optical diffraction, and monochromatic and chromatic aberrations. Using the far field diffraction phenomenon, and a simple eyepiece with a reticle appropriate to the used diffraction pattern (straight fringes or a pattern with rotational symmetry), the need for refocusing, and hoping that the generated line would not be affected by this action, was obviated, and very cheaply a satisfactory accuracy was obtained. Moreover, even when alignment has not been yet reached, information about how to displace the observer's eyepiece is available. The majority of the earlier methods lack this information on how to displace components during the non-alignment situation. By using a correctly placed field stop near the eyepiece, aligning can also be performed in broad daylight, which can not be done using most of the earlier methods. Starting with Thomas Young's slits directly after the war, damaged bridges were straightend and provisionally repaired. Also historic church towers were inspected using this simple alignment method, in order to see whether dangerous changes in the tower structure occurred during ringing of the bells and during stormy weather. In later years, projects such as the alignment of the runways of Amsterdam Airport, the alignment of the slope and 
railtracks supporting the enormous rolling basins, each carrying four freightvessels up- and downhill somewhere between Belgium's coal mine district and the port of Antwerp, and for many others, different alignment equipment was used. The most popular set up used a zone plate (not a Fresnel type, because that generates foci along the line to be generated), consisting of concentric transparent and opaque rings, giving a far field pattern with rotatory symmetry. In later years, also spherical aberration, generated by lenses or mirrors, was used to generate lines and planes. Interestingly, the use of rainbows generated through double reflections within glass spheres or concave mirrors, could also be used to align planes when observing the edge of the fringe pattern. With mirrors, a white rainbow can be generated!

Although it didn't lead to research pursued over a long period, such as was the case with the subjects mentioned above, it is worth noting that Van Heel developed the principle of fibre optics, as is shown in his publication in e.g. Nature, Vol. 173, page 39, (1954). A complete list of Van Heel's publications appeared in Applied Optics, Vol. 6, No. 5, page 800-803, May 1967.

\section{Teaching}

Van Heel was a born teacher in the best sense of the word. His lectures for first- and second year physics students on physical and geometrical optics were fully covered by his famous textbook "Inleiding in de Optica" (Introduction to Optics), and one could very well pass an exam in Optics without attending class. However, the lecture room was always completely filled with students, even coming from other faculties, because his presentations were very entertaining. Theory was always illustrated with many experiments spiced with anecdotes, historical background information and penetrating questions and statements. For new lectures, his ratio between preparation time and lecture time was at least five to one, and when giving an already worked out lecture, the ratio never was smaller than two to one. His meticulous lecture planning can be illustrated by the following. He always gave on one day two lectures, separated by an intermission. When introducing the eye and vision, the lecture took place on the day of the cattle market in Delft. During the first lecture hour the theory and description of the eye was given and a technical assistant went to the market's slaughterhouse to obtain a few cow's eyes. During the intermission, Van Heel dissected parts of the eyes in such a way, that one could look through the eye and see the reverse image on the retina. The eyes were stitched to a little frame, immersed in alcohol in a glass cuvette with flat walls. This arrangement was then passed on in the lecture room, and everyone could see for himself the limitations and strongpoints of imaging on a curved surface, the field of view, the function of the eyepupil, etc. Another item was a small but convincing set up of Young's interferometer, handed out in the lecture room for "seeing with your own eyes what happened". To rule out reactions like "This is of course a slide he is showing us", a hole in one of the sideplanes of the boxlike set up, enabled to convince his audience that dirty tricks had not been used and that the fringes really were generated by the tiny interferometer held by the student. As said earlier, also students from other faculties attended his lectures without any necessity to pass an exam in Optics. A much wider circle than just the physicists was charmed by him and remembered during their later professional careers the versatility and applicability of optical theory and techniques. 
To my opinion this popularity, also with non physicists, explains the many questions put to him and his department by alumni involved in projects, where "may be" optics could be of any help.

He also gave lectures to fourth and fifth years students in Technical Optics and to students of Geodesy. These where given in his study, and also there experiments were set up and demonstrated by him.

In his department Van Heel "managed by walking around", by putting questions to you, long enough to find out whether you really knew what you were doing. As soon as you started to hesitate in answering, he had convinced you that you had overlooked something or that your knowledge was not good enough yet for tackling the problem. When a student chose Optics for his M.Sc. work, he/she had to design in most cases either an optical system or an optical measuring instrument. After the design phase came the constructing phase (getting experience about how to get (parts of) your design built in workshops). Then came the test- and verification phase, and last but not least the writing of the M.Sc. thesis, which could be used by someone else as user manual. In this way Van Heel's department created a great variety of useful optical equipment, that also could be loaned to groups outside the department, thereby again enhancing the popularity of optics. To name two examples: Airflow photography and air density measurements in wind tunnels of the Aeronautics Faculty and miniaturized polarization measuring equipment to determine in a cryostat the birefringence of single Helium-4 crystals, in the Low Temperatures department.

\section{Closing remarks}

Professor Bram van Heel has had a significant positive influence on the development, the acceptance, and the application of optics. His charming personality and his expertise won him the esteem and friendship of scientists and engineers all over the world, and his influence is still noticeable today in their work and in the work of their successors. 


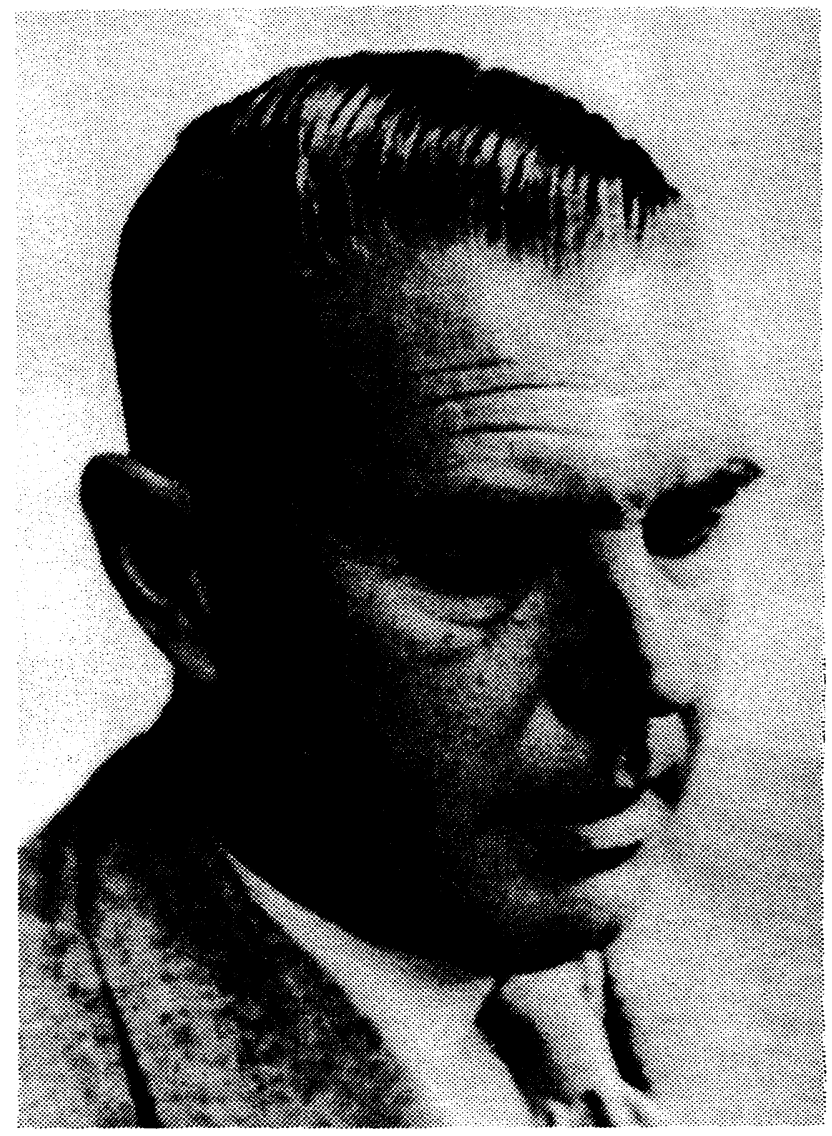

\section{A.C.S. van HeeI}

